\title{
The Practice and Politics of Urban Climate Change Mitigation and Adaptation Efforts: The Case of Cairo
}

\author{
Marwa Dabaieh $^{1} \cdot$ Dalya Maguid $^{2} \cdot$ Rasha Abodeeb $^{3} \cdot$ Deena El Mahdy $^{2}$
}

Accepted: 3 September 2021 / Published online: 26 October 2021

(c) The Author(s) 2021

\begin{abstract}
Research on climate change mitigation and adaptation is pressing in order to understand its implications and risks in different urban areas. It is especially critical for those who face high degrees of urban inequality in the context of an uneven state presence. This paper is an explorative and investigative study which uses Cairo as a case. The focus of the study is on mapping state and private sector efforts in mitigating climate change issues, specifically for vulnerable groups who have limited access to public services. The study adopted an investigative approach where a literature search and bibliometric mapping were used to identify the gap in knowledge in the field of architecture and urban climate change mitigation and adaptation, followed by a field survey which included conducting interviews and questionnaires with different stakeholders from the public and private sector to investigate the link between the efforts for climate change mitigation. The explorative part of the study concluded that there is a huge knowledge gap in the Middle East and in Egypt when it comes to research efforts related to climate change with a focus on the built environment. The results of the investigative part of this study revealed that-apart from already limited efforts on ground-there is no synchronization in efforts between the public and private sector. Climate change issues are still not a priority when poverty, economy, and health are still a prime concern and take precedence over climate change. There is uneven presence of public efforts for climate change adaptation and mitigation. The efforts that do exist in the public sphere are self-help unorganized work (efforts) conducted by the civil society.
\end{abstract}

Keywords Climate change $\cdot$ Mitigation $\cdot$ Adaptation $\cdot$ Egypt $\cdot$ Built environment

Marwa Dabaieh

Marwa.dabaieh@mau.se

Extended author information available on the last page of the article 


\section{Introduction}

Climate change is the most pressing environmental problem facing the world today and needs to be addressed using different approaches and methods (Bache et al., 2016; Percival et al., 2017; Zen et al., 2019). Rapid urbanization and population growth in the last few decades have forced several cities and countries globally to pay more attention to the consequences of climate change (Garshasbi et al., 2020; Mi et al., 2019; Xu et al., 2019). Direct and indirect effects of climate change can include changes in mean temperatures, sea levels, precipitation, cyclones, droughts, heat waves, cold waves, and exposure to population movements and biological changes (Martínez et al., 2018). NASA's Goddard Institute for Space Studies found that global surface temperatures in the past decade are $0.8{ }^{\circ} \mathrm{C}$ higher than at the start of the twentieth century (Carter et al., 2015). According to WMO (2020), the global mean temperatures have risen for 2019 by $1.1 \pm 0.1{ }^{\circ} \mathrm{C}$ above the pre-industrial levels. Furthermore, the past decade (2010-2019) has shown the warmest temperatures on record. Consequently, heat waves, shifts in rainfalls patterns, floods, droughts, sea level rise, greenhouse gas emissions, and many other implications are expected to threaten not only ecosystems, but also societies. Many scientific studies have also noted that green house gas emissions, which have increased in the last century due to human activities, are heavily responsible for global warming and heatwaves (UN-Habitat, 2011).

Cities and urban centers are considered important sites that need to be addressed in the global response to climate change (Broto \& Bulkeley, 2013; UN-Habitat, 2011). Several studies have suggested the link between urbanization, the rate of carbon emissions, and the impact on climate change in regions and cities ( $\mathrm{Xu}$ et al., 2019; Zen et al, 2019). Cities are particularly vulnerable to the adverse effects of climate change and urbanization, as more than half of the world's population live in cities and are exposed to its direct effects (Martínez et al., 2018; Hunt \& Watkiss, 2011; UN DESA, 2014). In addition, cities are among the major contributors of carbon emissions and consume $67 \%-76 \%$ of global energy and generate around $71 \%-76 \%$ of $\mathrm{CO}_{2}$ emissions (Xu et al., 2019; Seto et al., 2014; UN-Habitat, 2016a). Consequently, various efforts have been made to expand our understanding of climate change impacts on towns and cities. Through these efforts, many issues were recognized such as the vulnerability of different sectors to the impacts of climate change, including agriculture, energy, urban planning and transport, waste, and building design.

Several researchers have already acknowledged the importance of developing climate change mitigation and adaptation strategies to reduce the effects of greenhouse gas (GHG) emissions (see Grafakos et al., 2020; Xu et al., 2019; Carter et al., 2015; Solecki et al., 2015; Lee \& Painter, 2015). Mitigation is concerned with reducing and stopping current and future GHG emissions at the root of their cause, mainly through policies (ESCWA, 2013; Schwirplies, 2018; Zen et al., 2019), while adaptation, on the other hand, is concerned with dealing with the adverse effects of climate change on a more local level to cope and adjust to the resulting climate impacts (ESCWA, 2013; Nyong et al., 2007). 
Egypt and other developing countries are also facing the threats of climate change. Research indicates that a rise in temperatures between 3 and $9{ }^{\circ} \mathrm{C}$ is expected to take place in the MENA region by 2100 , which is double the previously expected $4{ }^{\circ} \mathrm{C}$ increase for the area (Ozturk et al., 2018). In addition, many cities across coastal areas in the Mediterranean and Nile Delta areas of Egypt are at a high risk of sea level rise and climate variability (Marcos et al., 2015; Frihy \& El-Sayed, 2013; Abdrabo \& Hassan, 2015). Also indicate that based on data retrieved from the Egyptian Meteorological authority (EMA), extreme weather events have also become more frequent and/or severe over Egypt. These include more intense heat waves, less frequent and intense cold waves, floods, droughts, and wild fires (Zaki et al., 2017). The IPCC (2015) asserts that in order to meet global climate change mitigation goals, both developed and developing countries need to take action. Thus, it is imperative for developing countries such as Egypt to implement global and local policies towards climate change mitigation efforts. Not only do mitigation efforts require a level of cooperation between different countries on a global scale, but also a cooperation between different levels of the government and the private sector on a local scale (Broto \& Bulkeley, 2013). Furthermore, according to Ostrom (2010), a single approach for mitigation strategies cannot be implemented in the same manner for all cities. It is essential for cities' different socio-economic and physical attributes to be reflected in the formation of their respective climate policy. Therefore, it is essential to have cooperation between local experts, local research communities, and policy makers in urban climate change governance (Lee \& Painter, 2015). Research also highlights the growing interest in assessing climate change adaptation and mitigation plans at the local level (Geneletti \& Zardo, 2016; Pasimeni et al., 2019 ) in addition to the need for local climate actions conducted by cities to try out best practices as well as new ideas.

Thus, this study aims to investigate climate change mitigation efforts made by the sector in cities, using Cairo as a case study. A mixed explorative and investigative research method was used, which included desk and field work completed between 2018 and 2020. The primary entry point for gaining a better understanding of how climate change is broached in Cairo was to examine the definitions and practices deemed to limit joint efforts between the public and civil society to tackle climate change. As climate change governance is a new topic in Egypt, through extensive literature mapping and field surveys, this study aims to offer a holistic understanding of how policy makers in the public sector operate.

\section{Literature Review}

\section{International Efforts in Addressing Climate Change}

Different approaches have been initiated by the global community to help mitigate climate change. In 1992, the United Nations Framework Convention on Climate Change (UNFCCC) agreed to stabilize GHG emissions to mitigate their impact in the atmosphere. The agreement involved different developed and developing countries; however, it is important to note that gas emission amounts vary from 
one country to another. In 1997, the Kyoto Protocol emerged from the (UNFCCC) requiring thirty-eight countries to reduce their GHG emissions (Akimoto, 2012). These steps were followed by several actions from the EU aiming to reduce expected GHG emissions in 2020 to around 20\% lower than 1990 levels. By 2030, they were expected to have reduced emissions to $40 \%$ lower than 1990 levels. As a result of this legislation, the EU introduced policy to increase the use of renewable energy (Akimoto, 2012). Furthermore, in 2016, the Paris Climate Agreement (UNFCCC, 2015) on international climate policy was officially put into effect. The agreement was considered a global achievement for climate change response and increased the need for countries to identify solutions and take actions in order to reach the emission targets put in place (Schwriplies, 2018; Xu et al., 2019). Municipal networks were created like the C40 Cities Climate Leadership Group, which connected more than 80 mega cities to one another and designated $25 \%$ of the global economy to address climate change and promote urban actions that reduce GHG emissions and climate risks. In addition to the Local Governments for Sustainability (ICLEI), which has a network of more than 1500 cities in 86 countries concerned with building a sustainable low carbon future (Bulkeley et al., 2009), other initiatives include the engagement of several city governments to take action on climate change mitigation. At both national and local levels, organizations such as WHO, UNESCO, UN-Habitat, and the IPCC, with the private sector, and with NGOs are working on climate-related policy (Zen et al., 2019). Especially the UN sustainability goals (SDG's) where SDG 13 is on climate action and sets a baseline for all UN Agency work even though the response to climate change on the international level can be considered relatively recent, several studies were found to address issues regarding climate change and cities (Broto \& Bulkeley, 2013). Cities vary in characteristics and thus implement different urban policies. These characteristics should be considered when developing urban climate governance, and urban planning policies and solutions to mitigate climate change in urban areas (Fuji et al., 2017).

Several studies were found to be concerned with adaptation and mitigation efforts in cities. These include studies on national climate policies for urban sustainability in different countries (See Bulkeley \& Bestill, 2005; Nevens et al., 2013; Gustavsson et al., 2009). Broto and Bulkeley (2013) conducted a survey of climate change initiatives and experiments in 100 cities worldwide to identify climate change mitigation efforts. Wu et al. (2016) noted the need for multi-level approaches to fight climate change impacts. Martínez et al. (2018) suggested that good urban climate governance requires the implementation of adaptation strategies and policy measures that involve societal, economic, and lifestyle changes. To achieve sustainable development, these would require the participatory support of urban residents. Thus, understanding people's attitudes and opinions on climate change is important. Zen et al. (2019) also highlighted the importance of having proper strategic plans, spatial plans, and a combination of mitigation and adaptation initiatives to be able to tackle climate change in urban areas in the coming years. Furthermore, the coordination between strategy and policy at several levels of government was noted as essential for successful climate change mitigation in cities (Colenbrander et al., 2017; Gouldson et al., 2015; Jänicke, 2015; Zen et al., 2019). The World Bank also highlighted five sets of solutions 
that should be addressed when tackling urban climate change mitigation efforts. These include the following: (1) increasing the urban density; (2) urban design that avoids sprawl; (3) enhancing public transport; (4) changing building practices; and (5) changing energy sources (UN-Habitat, 2016a; Banhardt \& Hartenstein, 2016).

In parallel, although some literature has discussed the possible tradeoffs and conflicts between combining mitigation and adaptation policies and practices in urban areas (Landauer et al, 2018; Landauer \& Juhola, 2015; Sugar et al., 2013; Dymen \& Langlais, 2013), several other studies have stressed the importance of adopting an integrated approach that combines mitigation and adaptation measures in urban areas. Landaeur et al. (2018) highlighted that while integrating mitigation and adaptation policies can be challenging, it is needed. Grafakos et al. (2020) applied the "urban climate integration index" to help assess and identify synergies and benefits of applying integrated adaptation and mitigation policy objectives in urban areas. Endo et al. (2017) investigated the potential link between adaptation and mitigation policies at the local level in urban areas and in particular in land use planning and management. Similarly, Cremades \& Sommer (2019) presented a tool to enhance urban planning and the design of climate smart urban forms that would also help in the development of mitigation strategies for cities. Garshasbi et al. (2020) stressed the importance of combining mitigation and adaptation techniques with more effective urban heat mitigation technologies to address the complexity of urban energy systems. Xu et al. (2019) studied the integration of climate change mitigation and adaptation in urban land use planning quantitatively while examining the possible tradeoffs and opportunities. Demuzere et al. (2014) and De la Sota (2019) investigated the benefits of green urban infrastructure as a means for climate change mitigation and adaptation.

Possible actions for urban governance policies and planning were also highlighted in the literature. Gopfert et al. (2019) examined the role that municipal advisory committees can play in the decision-making process for the integration of climate change mitigation and adaptation goals in sectoral policy and planning. Lee \& Painter (2015) studied the influence of urban climate change governance arrangements that include NGOs along with public officials on city level climate change policies. In addition, Pasimeni et al. (2019) contributed to the concept of comprehensive urban climate policies by proposing a new classification model of climate change mitigation and adaptation measures that helps in classifying best practices done on an urban level. Schwirplies (2018) highlights the factors that affect the acceptance of national and international climate change adaptation and mitigation policies through a cross country analysis between China, Germany, and the USA. However, other literature still suggests that while the benefits of providing integrated approaches in climate change planning have been highlighted in multiple studies, there is still only a minority of cities who consider climate policies in their action plans and fewer that actually implement the integration of adaptation and mitigation plans (Grafakos et al., 2020; Mendizabal et al., 2018). Thus, it is apparent that there is still a need for more studies that focus on mitigation and adaptation efforts. 


\section{Egypt's Actions in Addressing Climate Change}

Egypt is located in Northern Africa and has a total area of $1,001,450 \mathrm{~km}^{2}$. It is bordered by the Red Sea and the occupied land (Palestine) to the East, by Libya to the West, by the Mediterranean Sea to the North, and by Sudan to the south. Most of Egypt's population is concentrated in the narrow Valley and the Delta of the Nile River, which comprises $5.5 \%$ of the total area in which agricultural lands and dense cities are located (EEAA, 2010). Egypt has limited water resources and long coastlines, which make it particularly vulnerable to climate change (Banhardt \& Hartenstein, 2016). Furthermore, as a result of the prevailing climate change consequences and temperature changes, increased extreme weather events, such as heat waves, sandstorms, rock slides, flash floods, and heavy rains, are predicted to take place in the future (WBG, 2020; Giza Governorate, 2018). UN-Habitat (2011) also mentions that sea level rise projections for 2030-2050 will greatly affect the Nile Delta region, which includes several cities in Egypt, including Port Said, Alexandria, Rosetta, and Damietta. Alexandria was also included in UN-Habitat's ranking of top 10 cities most vulnerable to flooding and having an exposed population (Banhardt \& Hartenstein, 2016; UN-Habitat, 2011). It is also worth mentioning that although Egypt has minimal contribution to GHG emissions, the impacts of climate change could be disastrous to the country. This is due to its population growth, limited fertile lands, large areas of desert, limited water sources, and in the country's vulnerability to sea level rise on the Mediterranean coast and the Nile Delta areas where most economic activities take place (WBG, 2020).

Taking into account the climatic situation and the expected consequences, considerable efforts were undertaken by the Egyptian government to join the international pace in order to understand the expected impacts and vulnerabilities of climate change. In 1992, Egypt signed the United Nations Framework Convention on Climate Change (UNFCCC) that was held in Rio de Janeiro (EEAA, 1999), and from 1995 to 1998, Egypt was an active member in four sessions of the international conference of parties (COP), which aimed to assess the progress in place for handling climate change. In 1999, Egypt also signed the Kyoto Protocol, which aimed to reduce signatories' GHG emissions. Egypt also put in place a climate change policy framework that is regularly updated, and is supported by the national strategy for adaptation to climate change and disaster risk reduction (MPMAR, 2018; UNDP, 2011). In 2010, the National Environmental, Economic, and Development Study (NEEDS) for climate change was created (MPMAR, 2018). In addition, Egypt developed its "Intended Nationally Determined Contribution" (INDC), which includes a set of measures set by each country to be applied to fight climate change in terms of both mitigation and adaptation and submitted them to the UNFCC in 2016 (Aboulnaga et al., 2019; WBG, 2020). Egypt's “Third National Communication" (TNC) was also submitted to the UNFCCC in 2016. The country also developed the "Sustainable Development Strategy (SDS)—Egypt's Vision 2030", which includes climate change related projects and programs for economic and environmental development by the year 2030. These projects are concerned with sustainable agriculture, protection of coastal zones, and efficient use of water resources (NAPGSP, 2018). Furthermore, the Ministry of Environment (MOE) in cooperation with 
the Ministry of Planning (MOP) are carrying out various initiatives to incorporate climate change adaptation into development planning processes, thus allowing climate change adaptation strategies, action plans and national development strategies, plans, and budgets to all be aligned together (NAP-GSP, 2018).

In line with the international Climate Agreements in place, Egypt submitted three reports to the United Nations Framework Convention on Climate Change (UNFCCC) (in 1999, 2010, and 2016). The first report (1999) mainly tackled GHG emissions and came up with a GHG inventory. The inventory classified the sectors that contributed most to GHG emissions, concluding that the energy sector had the highest contribution, followed by the agriculture sector, and the industrial sector (EEAA, 1999). The second report was concerned with more in-depth research studies and analysis for vulnerable sectors, sites, and stakeholders. Adaptation and mitigation strategies and policies were mentioned as well, and were developed according to national plans (EEAA, 2010). The third report focused on the multi-sectoral nature of climate change impacts. This last report aimed to understand the vulnerability of each sector and its adaptation and mitigation possibilities based on the most recent research available (EEAA, 2016). The report recommended the development of a Climate Change Adaptation Policy Framework (CCAPF) to set certain rules and responsibilities, engage different stakeholders, and define available possibilities for financial support (EEAA, 2016). The report also draws attention to the vulnerability of urban areas in Egypt, particularly where there is a rapid increase in urban population and a number of informal settlements and slums where the urban poor and socio-economically marginalized groups reside. Therefore, the link between the governmental level, community organizations, and local non-governmental organizations should be enforced to exchange knowledge and capitalize on local insight and experiences (EEAA, 2016).

Examples of a few national mitigation strategies that are already in place include the national policy for switching from oil to natural gas, which has already been implemented in the transportation, industrial, and housing sectors. Also, the extension of the underground metro lines to new areas in Greater Cairo to help improve energy efficiency in the transport sector and promote the use of public transportation (MPMAR, 2018). Expansions are also taking place in the utilization of renewable energy such as solar and wind power energy. A large-scale grid-connected wind farm for instance is already in place in the Zaafarana area (EEAA, 2010). Other initiatives include implementing the feed-in-tariff program to facilitate the widespread use of photovoltaic cells, wind power generation, and waste management projects (MPMAR, 2018), in addition to the shift of some cities, such as El-Gouna city for example, to becoming Carbon neutral cities (WBG, 2020; EEAA, 2016).

The housing sector was also recognized as part of the national plan, and between 1996 and 2016, Egypt decided to reduce the population of the greater Cairo area by constructing five new cities in the desert with their own facilities, industrial zone, and housing projects. These cities include 6th of October, 15th of May, El-Obour, the 10th of Ramadan, and El Sadat (EEAA, 2010). Additional cities were developed to accommodate certain economic activities and attract population numbers, such as Al-Mahala Al-Koubra and El-Mansoura for agribusinesses, Suez and Port Said for transportation activities and Sharm El-Sheikh, Hurghada, and Luxor for touristic 
activities (EEAA, 2010). By 2020, El-Sherouk City and Madinaty were also developed, with New Alamin and the New Capital under construction. The creation of most of these cities were considered adaptation measures to climate change and accordingly were designed to be green and energy sustainable following the criteria for sustainable cities (MPMAR, 2018). However, post-construction investigations reveal that, in practice, this is not really what was implemented. Rather, the most significant achievement in the housing sector was that the Ministry of Housing, Utilities, and Urban Communities issued a code for saving energy in buildings through recommendations for building orientations and using natural lighting and natural ventilation yet not mandatory. Participatory development programs in urban areas (PDP) (2010-2018) are also being implemented by the Gesellschaft für Internationale Zusammenarbeit (GIZ), the Ministry of Housing, Utilities and Urban Communities, and the Ministry of Environment (NAP-GSP, 2018). Furthermore, the Giza governorate in collaboration with the GIZ developed the document "Climate change strategy framework in Giza governorate" to help mainstream climate change in project planning at the governorate level (Giza governorate, 2018). The Arab Framework Action Plan on Climate Change (AFAP-CC; 2010-2020) was also developed by the LAS CAMRE, in collaboration with UN agencies as a strategic regional climate change framework to organize climate action in the Arab region. Part of this action plan is the "Arab strategy for housing and sustainable urban development", which Egypt is a contributor and member of (UN-Habitat, 2016b). The strategy aims to identify the sustainable development goals in the Arab Region and presents a framework for joint Arab action in housing and sustainable urban development. This is done through addressing key challenges that face housing and urbanization and setting and developing goals to meet the context of each country at the national level (UN-Habitat, 2016b).

Although the topics of climate change, green architecture, and sustainable design and urban planning are still not fully implemented, they have become a major topic of interest for researchers and research centers (EEAA, 2010). In terms of urban mitigation and adaptation, review of the literature indicates that some studies have broached this topic in relation to Egypt. Khalil et al. (2018) investigated the results of climate change-induced heat stress for urban dwellers in informal areas in Cairo, noting their vulnerability and the importance of studying environmental performance in the outdoor microclimate of these areas. The study shows that the urban heat island effect increases from the effects of climate change in the microclimate of cities, particularly in the street space. Fahmy et al. (2014) investigated the adaptation opportunities for climate change in Egyptian urban communities through vegetative cover while highlighting their possible impact on energy efficiency in homes. Fahmy et al. (2020) addressed outdoor microclimates as well, but in relation to the effect that urban canopy green coverage has on energy consumption in residential buildings in Alexandria. The paper suggests that the use of urban canopy green coverage such as green facades, green roofs, and surrounding trees and green elements could enhance outdoor microclimates and reduce indoor energy consumption, thus helping mitigate climate change. Similarly, Fahmy et al. (2017) investigated adaptation opportunities for Egyptian urban communities through the use of vegetative cover through its impact on residential energy efficiency. Aboulnaga et al. (2019) 
presents an overview of recent adaptation policies and measures in Egypt related to settlements and infrastructure, water resources, ecosystem and tourism, agriculture and green spaces, and health sectors. While, as previously noted, some studies were found in the fields of climate change adaptation and mitigation in Egypt, there is still a need for more research in this area, particularly on the actual implementation of these measures and policies.

\section{Methodology}

This research employs an explorative and investigative qualitative approach using an extensive literature review, bibliometric analysis, and interviews as the three main tools for data collection. A literature review (explorative) was firstly conducted on published material on climate change adaptation and mitigation strategies worldwide, followed by a literature review focused on the Egyptian case. This explorative baseline provided an overview of where Egypt stands in regard to urban climate change adaptation and mitigation measures in comparison to the rest of the world. To illustrate the bibliometric analysis, VOSviewer was used for publications within the fields of climate change adaptation and mitigation worldwide, as well as in the Middle East and Egypt. The bibliometric analysis was followed by semi-structured interviews with diverse stakeholders. A critical content analysis was used for both the literature material and transcription of the interviews.

\section{Literature Scanning and Mapping}

The semi-extensive literature search included, but was not limited to, journal articles, published books, conference proceedings, organizations' or NGOs' project, technical or progress reports, and governmental reports. Next, the bibliometric analysis confirmed gaps found in the topic of climate change adaptation and mitigation within the Egyptian context compared to the Middle East region and worldwide. The search targeted specific information on climate change, urban adaptation, mitigation policies, and government policies, as well as grass roots initiatives, activist movements, NGOs' efforts, and local adaptation measures and citizens' coping mechanisms. The research is mainly centered on the Egyptian case, with a more specific focus on the greater Cairo area.

\section{Mapping for Publications}

The methodological framework for mapping the publications aims to investigate climate change adaptation and mitigation research efforts in Egypt in connection to broader worldwide movements. The use of mapping here is to address the limitation of the research topics of urban adaptation and mitigation in Egypt related to climate change in the built environment. Bibliometric analysis was employed to compute where gaps exist in the field, particularly within published journal articles. Similar bibliometric techniques have been used by researchers studying business models 


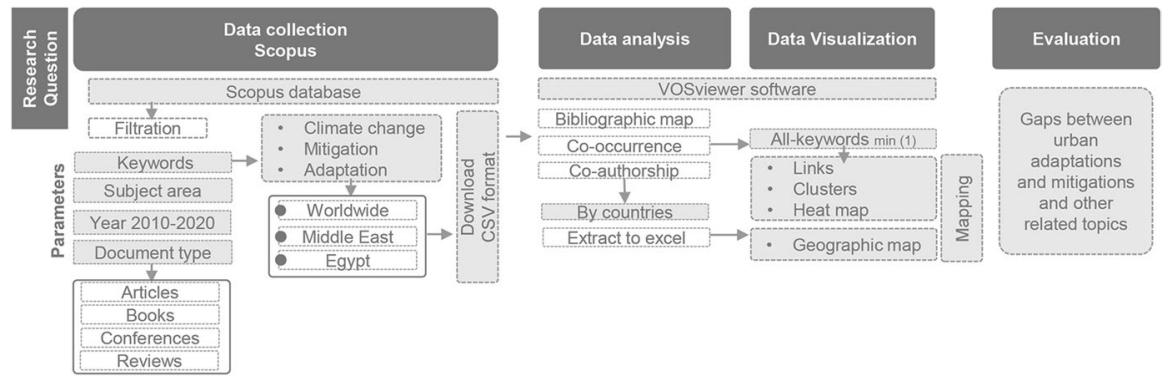

Fig. 1 Mapping process using VOSviewer software

for electric cars, carbon emissions, and environmental management based on Big Data, global journal maps from Web-of-Science data, and deep-narrative analysis in energy policy research (e.g., Secinaro et al., 2020, Su et al., 2020, Leydesdorff \& Rafols, 2012, and Debnath et al., 2020 respectively). Bibliometric analysis helps in the identification of the quantitative variables involved in a theme through determining the necessary information including authors, number of publications, countries, and keywords, and includes combination of these variables as part of the analysis. This study used the same method of mapping as Aria \& Cuccurullo (2017), Cobo et al. (2011), and Zupic \& Cater (2015), which follows four main phases: data collection, data analysis, data visualization, and evaluation. Figure 1 elaborates on the mapping process followed in this paper to extract the needed data to highlight research gaps using VOSviewer software.

\section{Data Collection Phase}

To evaluate the gaps in research on the topic of urban climate change adaptation and mitigation in Egypt, the Middle East, and worldwide, a set of parameters were set to filter matching data from the bibliometric extraction. "Climate change," "mitigation," and "adaptation" were used as search terms both in the title and keyword fields in the Scopus database. The co-occurrence of the keywords in the citation analysis were used to understand the network between the topics and geographic regions (i.e., global, Middle East or Egypt). The analysis period covers the last 10 years-between 2010 and 2020.

\section{Data Analysis Phase}

The data analysis type selected is the keyword analysis, which is considered one of the most accurate indicators of an article's main content according to ( $\mathrm{Su}$ et al., 2020). The Scopus database was selected for the keyword search in this study since according to Sweileh (2021), the Scopus database is larger than WoS and includes all of the publications on Medline - a database related to biomedical information. It should however be noted that both Scopus and WoS have minor issues. While WoS is reported to have inaccuracies, missing references, and incorrect references, 
Scopus maintains some reference duplications (Van Eck \& Waltman, 2019). VOSviewer software, developed by Van Eck and Waltman (2009), is used to visualize and analyze quantitative data for bibliometric mapping and to simplify the process of exploring complex relationships. Unlike other available software, the main feature and strength of VOSviewer is that it allows over 100 references to be simply and visually displayed at the same time (Van Eck \& Waltman, 2009). The software is freely available and can generate a graphic representation of different bibliometric maps.

\section{Data Visualization Phase}

The co-occurrence network in VOSviewer allows the user to generate a set of clusters and relationships between the keywords from inserted documents. One or more keywords were selected to generate diagrams which highlight gaps in selected topics. Following this analytical procedure, focus was directed to one of the clusters to note the gaps in topics related to "urban" and "architecture" in connection to "climate change mitigation" and "climate change adaptation."

\section{Data Entry Evaluation Phase}

The keywords resulting from each cluster show the gap between urban climate change adaptation and mitigation, and other related topics. This data was filtered according to countries and was then exported to an Excel format for analysis and to generate a map of relevant geographies (i.e., geographies where research relating to "architecture" and "urban" in relation to "climate change adaptation" and "climate change mitigation" exists).

\section{Interviews}

Interviews were a key step in order to obtain more information on both the role of the government as well as individual practices to combat climate change. We were targeting civil servants as government officials at the Egyptian ministry of energy and environment, waste management, and housing, besides NGO representatives or founders when available. Also, we targeted university researchers and lecturers, Cairo municipality (Cairo Governorate) official representatives, architects, and engineers practitioners. A total of ten people, five women and five men, were interviewed, with 4-20 years of professional experience. Six of the interviews were conducted face to face, while four were held virtually. Interviewees were selected based on their job titles and professions. During each interview, the interviewee was asked to recommend other experts in the field of urban climate change adaptation and mitigation. Through this snowball technique, a sufficient number of interviewees were reached to provide an adequate amount of data and information for the purpose of this research. Following each interview, interviewees were also asked for recommendations on reading material, or published reports to support the interview analysis and earlier literature search. All the names were kept anonymous for reasons of privacy. The interview questions were sent in advance to the interviewees by 
email. Questions were mainly inquiring about information related to governmental efforts towards climate change mitigation and adaptation, including measures, strategies, and polices that have been developed by the government to adapt to climate change and mitigate climate change risks. The questions also covered whether or not the interviewee had contributed to any research or projects in the field of climate change, and if so, in which sectors (e.g., energy, transport, agriculture, health, waste management, water, housing, urban planning). The interviewees were asked if they participated in any climate change campaigns inside or outside the country or if they had worked with any other NGO, private sector firm, local community initiative, or university outside of their primary professional affiliation. It was not possible to record the interviews due to concerns early on from a few of the interviewees. Instead, notes were taken and then transcribed at a later stage. These transcriptions were then shared with the interviewees in case they had revisions to make and to ensure that they agreed with the material.

\section{Results and Discussion}

\section{Bibliometric Mapping}

During the literature review, it became apparent that climate change adaptation and mitigation as a topic of research was much more broadly and deeply covered by worldwide data compared to data focusing on the Egyptian case. Thus, it is posited in the study that there is a gap in the field, especially for cases in Egypt, which this study also aims to tackle.

\section{Topic and Category Filtration and Keyword Map}

The process used to filter references from the Scopus database for "climate change mitigation and adaptation" during the period from 2010 to 2020 showed a total of 5092 articles published worldwide. Twenty out of the total were published with a focus on the Middle East and 13 were published focusing on Egypt, as shown in (Fig. 2). However, while searching for "mitigation" and "adaptation" separately from climate change, more documents were found in both the Middle East (136) and Egypt (130). This differentiation is the result of intersection with a wider range of fields such as energy, agriculture, water, and health. Using the keywords "climate change mitigation and adaptation" in a search on documents published between 2010 and 2014 shows a total of 3 publications in both the Middle East and Egypt. While, after 2015, the number of publications significantly increased to over 23 publications, as shown in Fig. 2, these low numbers are the result of using "climate change mitigation and adaptation" as one keyword in the search rather than splitting them into different search terms. Figure 3 shows the dearth of publications which can be clearly observed (in Egypt \& the Middle East as opposed to other countries worldwide) between the different countries and both Middle East and Egypt. Also notable is that, in the last 2 years-from 2019-2020, the number of publications worldwide took a marked dip, decreasing to 430 compared to 680 at its peak in 2018. 
Fig. 2 Very few documents in the field of climate change mitigation and adaptation were published in Egypt and Middle East between 2010 and 2020

Fig. 3 Number of published documents in Scopus for the 3 set groups (Worldwide, Middle East, and Egypt) between 2010 and 2020
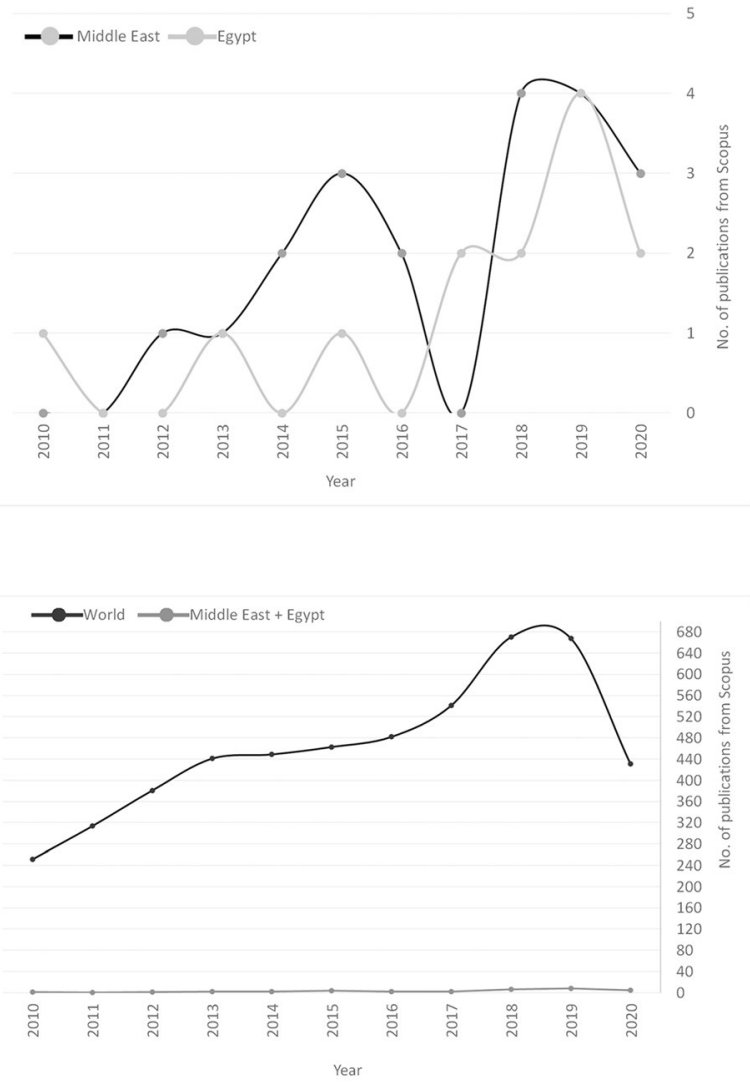

\section{Network Visualization (Cluster Topics and Links)}

The network visualization represents the hierarchical order and relationship between the keywords generated in cluster groups shown in Fig. 4. Each cluster includes a group of keywords related to a specific field. The closer the cluster is located to the main centered keywords, the easier it is to recognize the location and the strength of the cluster. The scale of the cluster is an indication of how frequently topics are covered in the area and the cluster number indicates how many keywords are inside it. At the global scale, around 8 clusters were observed resulting in 5092 articles focused on topics related to agriculture, urban planning and sustainability, food, energy, environmental policy, adaptation, climate policy, and water. While fewer articles were found pertaining to the Middle East, in the 136 articles that did turn up, most tackled topics related to sustainable design, urban and social environment, eco design, and climate mitigation. Table 1 shows the most common co-occurrence keywords appearing in articles in the 3 set groups. 


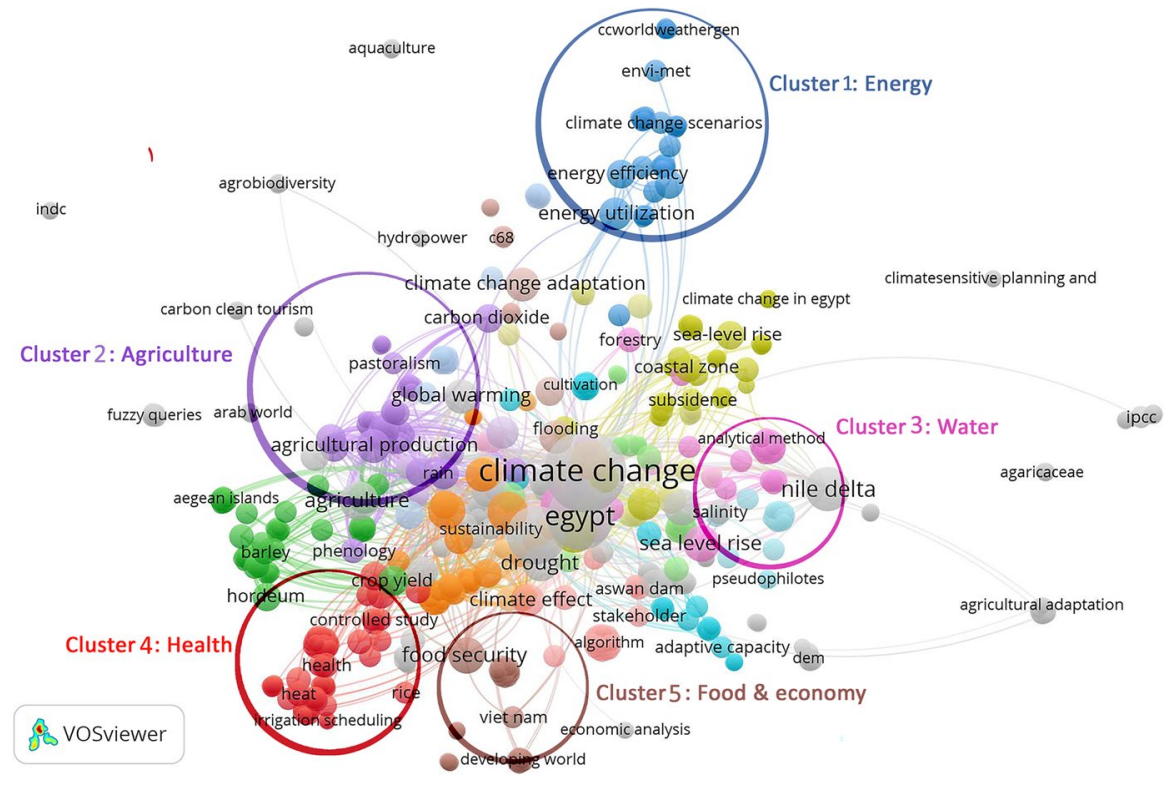

Fig. 4 Visualization of keyword clusters for Egyptian publications

It is observed that in one of the clusters, cases from Syria, Tunis, Yemen, and Libya showed some implementation of mitigation and adaptation measures. In Egypt, supplementary Fig. 4 reflects the clusters of 130 articles. Most of the topics in articles related to Egypt focused on energy, agriculture, health, food, and water. Very few publications were found on the topic of urban. As shown in cluster 1, results were particularly low for studies published between 2017 and 2020 on topics such as urban growth, urban environment, architecture and structure, global warming, world population, thermal conditions, and adaptation methods. More recently, publications seem to be trending towards topics related to environmental performance and management, residential developments, and indoor thermal comfort.

\section{Gaps in Urban and Architecture Topics}

The VOSviewer publications mapping shows that most topics related to climate change adaptation and mitigation are oriented to agriculture, food education, water, energy, environmental policy, archeology, and tourism. The connection between climate change adaptation and mitigation at the building and settlement (urban) scale was not found on a large scale in either the Middle East or Egypt. This indicates that both regions need to raise awareness on the importance of research and policies related to mitigation and adaptation strategies in connection to the built environment and urban growth. Although climate change mitigation and adaptations strategies have been applied in specific Egyptian cities such as Cairo, Alexandria, 
Table 1 Characteristics of the included studies

\begin{tabular}{|c|c|c|c|c|c|c|c|c|}
\hline \multicolumn{3}{|c|}{ Worldwide } & \multicolumn{3}{|c|}{ Middle East } & \multicolumn{3}{|c|}{ Egypt } \\
\hline Occurrences & total link & strength & Occurrences & total link & strength & Occurrences & total link & strength \\
\hline & 192 & 569 & Climate change & 16 & 291 & Climate change & 59 & 74 \\
\hline Climate change & 8 & 0 & Middle East & 6 & 148 & Egypt & 25 & 47 \\
\hline & & 371 & North Africa & 5 & 144 & Adaptation & 23 & 42 \\
\hline Adaptation & 990 & 9 & Global warming & 4 & 98 & Nile delta & 8 & 17 \\
\hline & & 291 & Middle East and North & & & Sea level rise & 6 & 11 \\
\hline Mitigation & 732 & 4 & Africa & 4 & 115 & Agriculture & 5 & 13 \\
\hline Climate change & & & Adaptation & 3 & 72 & Climate change & & \\
\hline adaptation & 192 & 463 & Agriculture & 3 & 75 & adaptation & 5 & 3 \\
\hline Vulnerability & 163 & 619 & Climate models & 3 & 95 & Vulnerability & 5 & 16 \\
\hline Resilience & 149 & 561 & Human & 3 & 104 & Drought & 4 & 7 \\
\hline Agriculture & 120 & 499 & Humans & 3 & 104 & Mitigation & 4 & 9 \\
\hline Sustainability & 116 & 404 & Population statistics & 3 & 76 & Sea-level rise & 4 & 4 \\
\hline Food security & 99 & 368 & Priority journal & 3 & 111 & Food security & 3 & 4 \\
\hline Global warming & 95 & 357 & Risk assessment & 3 & 107 & Lake Nasser & 3 & 9 \\
\hline Sustainable development & 90 & 329 & Adaptive management & 2 & 53 & North Africa & 3 & 6 \\
\hline Climate change & & & Africa & 2 & 72 & Salinity & 3 & 8 \\
\hline mitigation & 87 & 250 & Climate & 2 & 44 & Tourism & 3 & 8 \\
\hline Ecosystem services & 69 & 234 & Climate change & & & Wheat & 3 & 6 \\
\hline Policy & 68 & 274 & mitigation & 2 & 68 & & & \\
\hline Governance & 55 & 184 & & & & & & \\
\hline Climate policy & 54 & 148 & & & & & & \\
\hline Adaptive capacity & 43 & 159 & & & & & & \\
\hline Cities & 43 & 160 & & & & & & \\
\hline Paris agreement & 42 & 145 & & & & & & \\
\hline Environment & 41 & 138 & & & & & & \\
\hline Greenhouse gases & 40 & 179 & & & & & & \\
\hline
\end{tabular}

Aswan, Fayoum, Ismailia, Red Sea, Delta, Lake Nasser, Rashid, Gulf of Suez, Gulf of Aqaba, and Sinai, most of the strategies focus primarily on tourism and agriculture with only a few focusing on the urban sector.

Figure 5 shows the variation of the topics and how those topics have developed throughout the years. Figure 5 illustrates that, in 2016, publications were oriented towards solar radiation, energy efficiency, shading structures, the urban environment, and energy policy. In 2018, articles focused more on urban growth and energy utilization. In 2020, research topics centered on environmental management, environmental performance, and indoor thermal performance and comfort. Only few studies have tackled the topic of urban adaptation and mitigation. Its distance from the other clusters reinforces the claim of this paper that the research area on climate change adaptation and mitigation in both architecture and urban level requires more attention. 


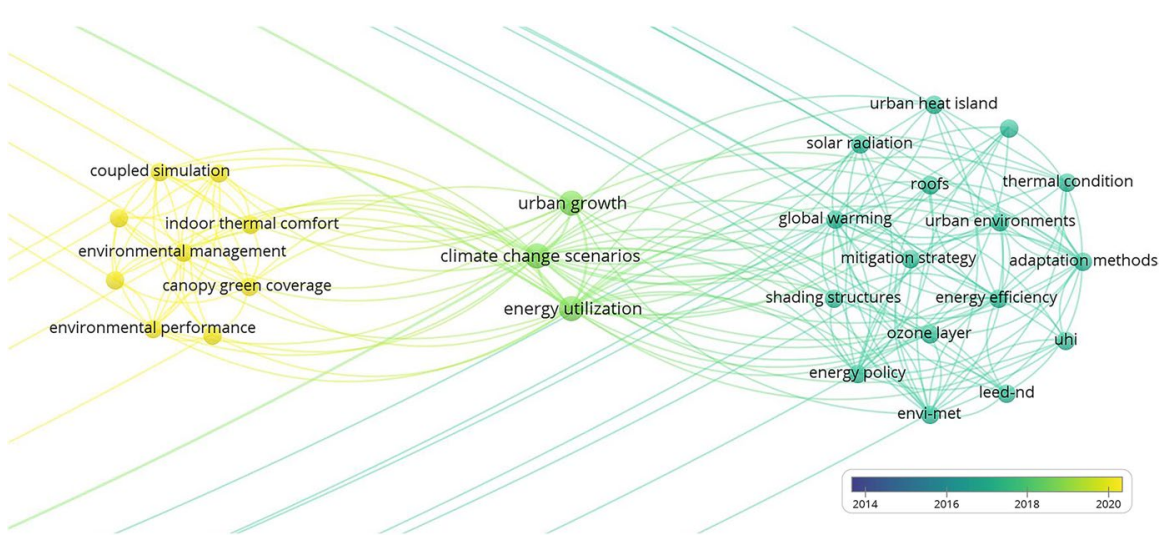

Fig. 5 Egypt cluster 1 (topics related to urban climate change)

Researchers working on Egypt tackled more topics related to the Middle East and North Africa (MENA region), specifically North Africa, where the application of climate change mitigation and adaptation in cities included research based in Libya, Tunisia, Jordan, Syria, Algeria, Lebanon, and the Eastern Mediterranean. As shown in Fig. 6, areas of focus included the relevance of climate change mitigation and adaptation in regard to agriculture, irrigation, and water, with few tackling themes related to urbanism and ecology.

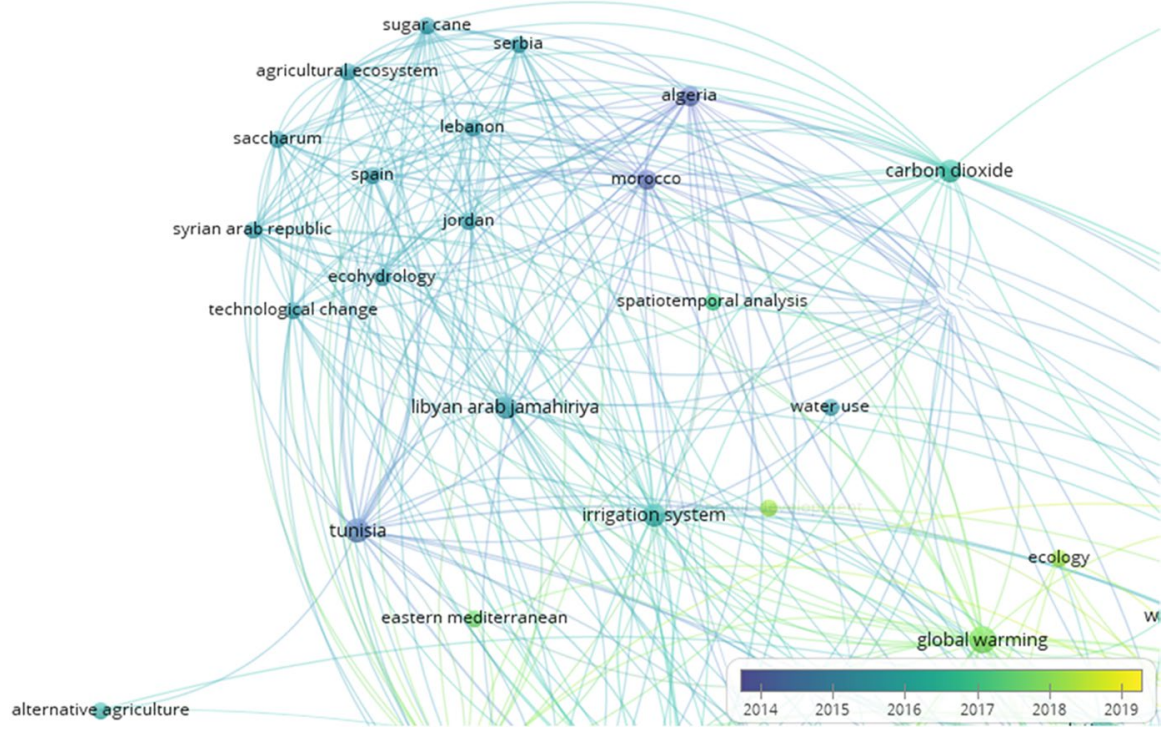

Fig. 6 One of the clusters related to research carried out in Egypt on the Middle East and North Africa 


\section{Interviews' Reflection}

In order to understand current dynamics between different stakeholders in this field, several interviews were conducted with government officials, representatives of NGOs and international organizations, and academic researchers and experts in the field. The interviews showed the roles of different stakeholders in Egypt working on issues related to climate change mitigation as well as their relationships with one another. The interviewees' responses also provided insight on recent governmental efforts in relation to current projects on climate mitigation and the challenges those projects face. Most importantly, outcomes from the interviews have revealed a considerable gap between the different stakeholders, not only in different sectors, but even in one sector. For instance, one of the government officials in the EEAA climate change department mentioned that "within EEAA, governmental bodies do not having a common understanding of what climate change is and what the risks and impacts in the very near future will be. Also, we are lacking the appropriate institutional structure to raise awareness, take serious steps, define responsibilities and roles, and monitor progress." Continuing in light of this misalignment, the official claimed, "we are working now on the institutional restructuring to activate and achieve the goals for the governmental agenda for adopting adaptation and mitigation strategies for climate change risks." Accordingly, the different sectors such as the energy sector, agricultural sector, and waste management sectors are simply working in siloes, with no coordination, synchronization, or monitoring.

The outcomes of the interviews fed into investigating the relationship between governmental institutions and NGOs. As illustrated in Fig. 7, there is an indirect connection between NGOs and governmental institutions whereby international funding organizations bridge the gap by maintaining a direct connection to both governmental institutions and NGOs. The actual role of governmental institutions is to approve (or reject) proposed projects, providing them with technical support when needed. In turn, NGOs always aim to accommodate the suggested projects in order to meet the current governmental interests and agenda. This is often done through funding organizations that provide technical support and or funding.

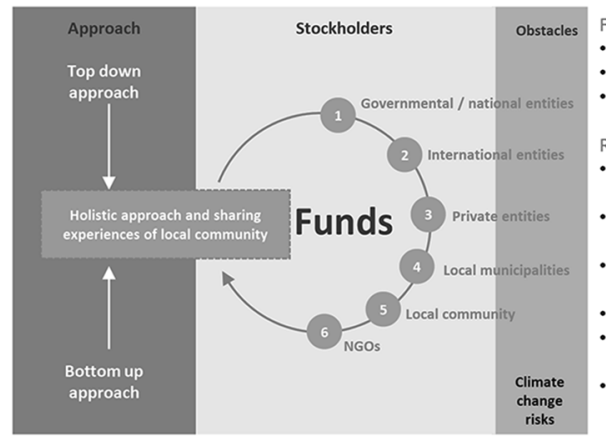

\footnotetext{
Findings:

Lack of awareness of the roles of 5 \& 6

Lack of awareness between (1) \& 4 about climate change risks.

Lack of governmental support in terms of maintenance support after finishing projects and delay in signing papers and approvals. Recommendation:

Restructuring the current governmental efforts to be more effective.

Coordinating between different governmental sectors to work together.

Allocate more funds for climate change mitigation and adaptation efforts.

Ambiguity of the governmental efforts, role and authorities. High rate of changing the governmental bodies in municipalities and generally in governmental institutions.

Sustainable solutions that related to economic aspect to ensure continuity.
}

Fig. 7 View of analysis outcomes revealing a few recommendations for a holistic approach to climate change adaptation and mitigation measures 
The interviews revealed the nature of ongoing projects within the current national/governmental agenda and interests. Most of the current projects are related to saving energy, rooftop farming, constructing biogas units in rural areas, planting trees, paving roads, and installing shading elements in streets. For instance, the national agenda aims for conventional incandescent lights to be replaced with LED lights; therefore, this intervention is considered to be one of the essential interventions that most NGOs are working on. The interview results also revealed the lack of awareness and knowledge on climate change adaptation and mitigation approaches across different sectors in the society and across entities involved with sustaining national projects on climate change mitigation and adaptation. Results also showed the incomprehensive approach and vision from the national level to effectively deal with climate change impacts. In addition, there are no clear plans in place to sustain these ongoing projects and interventions. One NGO representative mentioned that, "we can't guarantee the sustainability of our project because we couldn't convince the municipality to take care of the installed solar panels after we left the area. they [the city government] just don't want to take the responsibility of cleaning them from time to time." A representative from another NGO mentioned a similar problem, stating that, "actually it's not only a kind of laziness but also a lack of awareness, knowledge, capacity building and experience of how to deal with such new technologies and the knowhow of maintaining and sustaining such interventions." Thus, there is a lack of awareness and knowledge on different levels also showed the incomprehensive approach and vision from the national level to deal with climate change impacts effectively.

Throughout the interviews, it was clear that most of the NGOs we talked to were not fully aware of the national climate change mitigation and adaptation polices in Egypt. Furthermore, they did not seem to have a complete understanding of the measures that should be taken towards mitigating or adapting to climate change in urban areas. While they mainly work under the umbrella of sustainable development, which includes environmental aspects and enhancing quality of life, the link between sustainable development, enhancing quality of lif and climate change risks is still ambiguous. This study surmises that this is due to two main reasons: either a lack of knowledge and holistic understanding, or a lack of financial support to the climate change cause. The NGO representatives who were interviewed also mentioned that they are always keen to raise peoples' awareness about climate change adaptation. This is done through conducting campaigns, workshops, and giveaway brochures about how to conserve energy and water. In addition they also help locals to learn how to install light structures with tents to reduce heat gain, wearing white caps to protect themselves from sun exposure, and other small-scale interventions to minimize the risks as much as they can. Although such efforts cannot be dismissed, they are not enough to tackle the real problem. Some NGOs mentioned the fact that people in informal areas are making an effort to reduce heat gain (heat island effect) on their streets, making small-scale interventions out of necessity.

The interviews with architects and engineer practitioners together with academic researchers have revealed that policy makers and government officials deliver mixed messages. One of the interviewees mentioned that, after meetings with governmental sectors, such as Cairo Governorate and UUU (Urban Upgrading Unit), he 
realized that the government institutions "are not convinced with the idea of climate change." From their point of view, "we are a developing country that is already affected by the impacts of climate change caused by other countries; so don't ask us to take considerable measures to improve the situation of climate change when the impacts are global."

Interviews with government officials themselves consistently revealed stress on the talking point that Egypt is trying to grow economically, and this is the main target for the time being, not climate change mitigation. One of the government officials mentioned that, "Egypt's contribution to global warming is minimal or does not exist, so we are not really committed to making any steps in this regard." Another researcher also quoted that "the last minister of Environmental Affairs mentioned that we are not really concerned about mitigation measures as we are a developing country and we are not officially committed to do anything towards climate change mitigation and all we can do is adapt [to climate change]... we need to develop our economic status so that it is on par with other countries, so we don't have to follow any mitigation strategies."

One suggestion for introducing a more holistic understanding of the issue of climate change was made by one of the researches we interviewed, who stated "I think we need to change the language that we use to address climate change issues by selecting the topics that really matter to the government and local citizens ..., such as heat waves, how to deal with high temperatures, and how to reduce them [frequency of heat waves and high temperatures]." The researcher added that it is important to know how to sell the idea of climate change to fit the governmental agenda and priorities.

\section{Recommendations and Concluding Remarks}

From the research outcome, it can be concluded that both policy visions and intervention implementation processes in respect to climate change mitigation and adaptation are not consistent across Egypt. While policy makers claim that climate change mitigation can be ignored in favor of economic development strategies, it is clear that the holistic impact that climate change has on developing countries as well as developed countries cannot be ignored. However, this is not the prevailing strategy in other countries, where strategies tend to arise from the micro level (grassroots initiatives). The authors of this article thus assert, building on results from interviews in this study, that in the case of Egypt, academia should take responsibility to tackle climate change differently. We can conclude from both the literature search and interviews that grassroot initiatives and a bottom-up approach need to be paired with top-down approaches to realize more holistic outcomes. Additionally, a way forward needs to be charted to share the experiences of local community members. Such insider knowledge can often be overlooked, but provides invaluable insight into climate risks and how to manage them. In order to achieve this holistic approach, a set of recommendations in connection to our analysis of the interviews and literature search highlights the common challenges and obstacles as shown in Fig. 7. 
Acknowledgements We are grateful for the time and insight provided by the interviewees who met with the research team responsible for this study. Deep thanks to the architect Salwa Alhegazi for her efforts as a research assistant in the literature search and help in categorizing different sources.

Funding Open access funding provided by Malmö University. This study was supported by Svenska Forskningsrådet Formas

Open Access This article is licensed under a Creative Commons Attribution 4.0 International License, which permits use, sharing, adaptation, distribution and reproduction in any medium or format, as long as you give appropriate credit to the original author(s) and the source, provide a link to the Creative Commons licence, and indicate if changes were made. The images or other third party material in this article are included in the article's Creative Commons licence, unless indicated otherwise in a credit line to the material. If material is not included in the article's Creative Commons licence and your intended use is not permitted by statutory regulation or exceeds the permitted use, you will need to obtain permission directly from the copyright holder. To view a copy of this licence, visit http://creativecommons.org/licen ses/by/4.0/.

\section{References}

Abdrabo, M., \& Hassaan, M. (2015). An integrated framework for urban resilience to climate changecase study: Sea level rise impacts on the Nile Delta coastal urban areas. Urban Climate, 14(2015), 554-565. https://doi.org/10.1016/j.uclim.2015.09.005

Aboulnaga, M., Elwan, A., \& Elsharouny, M. (2019). Urban climate change adaptation in developing countries: policies, projects, and scenarios. Springer. https://doi.org/10.1007/978-3-030-05405-2

Akimoto, K. (2012) Mitigation Targets and Effort-Sharing Among Regions and Countries. In: Yamaguchi M. (eds) Climate Change Mitigation. Lecture Notes in Energy, vol 4. Springer: London. https://doi. org/10.1007/978-1-4471-4228-7_3

Aria, M., \& Cuccurullo, C. (2017). Bibliometrix: An R-tool for comprehensive science mapping analysis. Journal of Informetrics, 11(4), 959-975. https://doi.org/10.1016/j.joi.2017.08.007

Bache, I., Bartle, I., \& Flinders, M. (2016). Multi-level governance. Handbook on theories of governance. Edward Elgar Publishing.

Banhardt, C., \& Hartenstein, F. (2016). Improving sustainability concept in developing countries a makeshift approach to carbon accounting in Egyptian towns. Procedia Environmental Sciences, 34(2016), 152-163. https://doi.org/10.1016/j.proenv.2016.04.015

Broto, V. C., \& Bulkeley, H. (2013). A survey of urban climate change experiments in 100 cities. Global Environmental Change, 23(2013), 92-102. https://doi.org/10.1016/j.gloenvcha.2012.07.005

Bulkeley, H., \& Betsill, M. (2005). Rethinking sustainable cities: Multilevel governance and the 'urban' politics of climate change. Environmental Politics, 14(1), 42-63. https://doi.org/10.1080/09644 01042000310178

Bulkeley, H., Schroeder, H., Janda, K., Zhao, J., Armstrong, A., Chu, S., \& Ghosh, S. (2009). In: Cities and climate change: The role of institutions, governance and urban planning. World Bank Urban Symposium on Climate Change. World Bank Urban Symposium on Climate Change.

Carter, J. G., Cavan, G., Connelly, A., Guy, S., Handley, J., \& Kazmierczak, A. (2015). Climate change and the city: Building capacity for urban adaptation. Progress in Planning, 95(2015), 1-66. https:// doi.org/10.1016/j.progress.2013.08.001

Cobo, M. J., López-Herrera, A. G., Herrera-Viedma, E., \& Herrera, F. (2011). Science mapping software tools: Review, analysis, and cooperative study among tools. Journal of the American Society for Information Science and Technology, 62(7), 1382-1402. https://doi.org/10.1002/asi.21525

Colenbrander, S., Gouldson, A., Roy, J., Kerr, N., Sarkar, S., Hall, S., \& Mcanulla, F. (2017). Can lowcarbon urban development be pro-poor? The case of Kolkata India. Environment and Urbanization, 29(1), 139-158. https://doi.org/10.1177/0956247816677775

Cremades, R., \& Sommer, P. S. (2019). Computing climate-smart urban land use with the Integrated Urban complexity model (IUCm 1.0). Geoscientific Model Development, 12, 525-539. 
Debnath, R., Darby, S., Bardhan, R., Mohaddes, K., Sunnikka-Blank, M., 2020. A nested computational social science approach for deep- narrative analysis in energy policy research', SocArXiv.1-21. https://doi.org/10.31235/osf.io/hvcb5.

Demuzere, M., Orru, K., Heidrich, O., Olazabal, E., Geneletti, D., Orru, H., \& Faehnle, M. (2014). Mitigating and adapting to climate change: Multi-functional and multi-scale assessment of green urban infrastructure. Journal of Environmental Management, 146(2014), 107-115. https://doi.org/10. 1016/j.jenvman.2014.07.025

De la Sota, C., Ruffato-Ferreira, V., Ruiz-Garcia, L., \& Alvarez, S. (2019). Urban green infrastructure as a strategy of climate change mitigation. A case study in northern Spain. Urban Forestry \& Urban Greening, 40(2019), 145-151. https://doi.org/10.1016/j.ufug.2018.09.004

Dymen, C., \& Langlais, R. (2013). Adapting to climate change in Swedish planning practice. Journal of Planning Education and Research., 33(1), 108-119. https://doi.org/10.1177/0739456X12463943

EEAA- Egyptian Environmental Affairs Agency, 1999. In: The Arab republic of Egypt: Initial national communication on climate change prepared for the United Nations framework convention on climate change UNFCCC.

EEAA- Egyptian Environmental Affairs Agency, 2010. Egypt: Second national communication under the United Nations framework convention on climate change.

EEAA- Egyptian Environmental Affairs Agency, 2016. Egypt third national Communication under the United Nations framework convention on climate change.

Endo, I., Magcale-Macandog, D. B., Kojima, S., Johnson, B. A., Bragais, M. A., Macandog, P. B., \& Scheyvens, H. (2017). Participatory land-use approach for integrating climate change adaptation and mitigation into basin-scale local planning. Sustainable Cities and Society, 35(2017), 47-56. https:// doi.org/10.1016/j.scs.2017.07.014

ESCWA - Economic and Social Commission for Western Asia, 2013. Guide on climate change negotiations for representatives and negotiators from Arab Countries, New York. https://www.unescwa.org/ sites/www.unescwa.org/files/publications/files/e_escwa_sdpd_13_tp-10_e.pdf .

Fahmy, M., El-Hady, H., Mahdy, M., \& Abdelalim, M. (2017). On the green adaptation of urban developments in Egypt; predicting community future energy efficiency using coupled outdoor-indoor simulations. Energy and Buildings, 153(2017), 241-261. https://doi.org/10.1016/j.enbuild.2017.08.008

Fahmy, M., Mahdy, M., Mahmoud, S., Abdelalim, M., Ezzeldin, S., \& Attia, S. (2020). Influence of urban canopy green coverage and future climate change scenarios on energy consumption of new sub-urban residential developments using coupled simulation techniques: A case study in Alexandria. Egypt. Energy Reports, 6(2020), 638-645. https://doi.org/10.1016/j.egyr.2019.09.042

Fahmy, M., Mahdy, M., \& Nikolopoulou, M. (2014). Prediction of future energy consumption reduction using GRC envelope optimization for residential buildings in Egypt. Energy and Buildings, 70(2014), 186-193. https://doi.org/10.1016/j.enbuild.2013.11.057

Frihy, O. E., \& El-Sayed, M. K. (2013). Vulnerability risk assessment and adaptation to climate change induced sea level rise along the Mediterranean coast of Egypt. Mitigation Adaptation Strategies Global Change, 18, 1215-1237. https://doi.org/10.1007/s11027-012-9418-y

Fuji, H., Iwata, K., \& Managi, S. (2017). How do urban characteristics affect climate change mitigation policies? Journal of Cleaner Production, 168(2017), 271-278. https://doi.org/10.1016/j.jclep ro.2017.08.221

Garshasbi, S., Haddad, S., Paolini, R., Santamouris, M., Papangelis, G., Dandou, A., Methymaki, G., Portalakis, P., \& Tombrou, M. (2020). Urban mitigation and building adaptation to minimize the future cooling energy needs. Solar Energy, 204(2020), 708-719. https://doi.org/10.1016/j.solener. 2020.04.089

Geneletti, D., \& Zardo, L. (2016). Ecosystem-based adaptation in cities: an analysis of European urban climate adaptation plans. Land Use Policy, 50, 38-47.

Gopfert, C., Wamsler, C., \& Lang, W. (2019). Institutionalizing climate change mitigation and adaptation through city advisory committees: Lessons learned and policy futures. City and Environment Interactions, 1(2019), 100004. https://doi.org/10.1016/j.cacint.2019.100004

Gouldson, A., Colenbrander, S., Sudmant, A., Godfrey, N., Millward-Hopkins, J., Fang, W., Zhao, X., 2015. Accelerating low-carbon development in the World's cities. In: Contributing paper for seizing the global opportunity: Partnerships for better growth and a better climate. New climate economy. Retrieved from https:/community-wealth.org/sites/clone.community-wealth.org/files/downloads/ paper-gouldson-et-al.pdf Accessed, September 2021. 
Giza Governorate, 2018. Towards a climate change strategy in Giza governorate framework document. Giza: Giza governorate. Retrieved from https://egwuf.files.wordpress.com/2020/01/giza-climatechange-strategy.pdf. Accessed, September 2021,

Grafakos, S., Viero, G., Reckien, D., Trigg, K., Vigiue, V., Sudmant, A., Graves, C., Foley, A., Heidrich, O., Mirailles, J., Carter, J., Chang, L., Nador, C., Liseri, M., Chelleri, L., Orru, H., Orru, K., Aelenei, R., Bilska, A., Dawson, R. (2020). Integration of mitigation and adaptation in urban climate change action plans in Europe: A systematic assessment. Renewable and Sustainable Energy Reviews, 121(2020), 109623. https://doi.org/10.1016/j.rser.2019.109623

Gustavsson, E., Elander, I., \& Lundmark, M. (2009). Multilevel governance, network cities, and the geography of climate-change mitigation: Two Swedish examples. Environment and Planning C: Politics and Space, 27, 59-74. https://doi.org/10.1068/c07109j

Hunt, A., \& Watkiss, P. (2011). Climate change impacts and adaptation in cities: A review of the literature. Climate Change, 104(1), 13-49. https://doi.org/10.1007/s10584-010-9975-6

IPCC- Intergovernmental Panel on Climate Change. (2015). Climate change: Mitigation of climate change (Vol. 3). Cambridge University Press.

Jänicke, M. (2015). Horizontal and vertical reinforcement in global climate governance. Energies, 8(6), 5782-5799. https://doi.org/10.3390/en8065782

Khalil, H. E., Ibrahim, A., Elgendy, N., \& Makhlou, N. (2018). Could/should improving the urban climate in informal areas of fast-growing cities be an integral part of upgrading processes? Cairo Case. Urban Climate, 24(2018), 63-79. https://doi.org/10.1016/j.uclim.2018.01.007

Landauer, M., \& Juhola, Söderholm. M. (2015). Inter-relationships between adaptation and mitigation: A systematic literature review. Climate Change., 131, 505-17. https://doi.org/10.1007/s10584-015-1395-1

Landauer, M., Juhola, S., \& Klein, J. (2018). The role of scale in integrating climate change adaptation and mitigation in cities. Journal of Environmental Planning and Management, 62(5), 741-765. https://doi. org/10.1080/09640568.2018.1430022

Lee, T., \& Painter, M. (2015). Comprehensive local climate policy: The role of urban governance. Urban Climate, 14(2015), 566-577. https://doi.org/10.1016/j.uclim.2015.09.003

Leydesdorff, L., \& Rafols, I. (2012). Interactive overlays : A new method for generating global journal maps from Web-of-Science data. Journal of Informatics., 6, 318-332. https://doi.org/10.1016/j.joi.2011.11. 003

Marcos, O., et al., 2015. Project based learning in international context in sustainability and global economy. Time European summer school: A truly European learning experience. In: INTED2015 Proceedings, pp. 4266-4279. http://library.iated.org/view/ORTIZMARCOS2015PRO

Martínez, C. I., Pina, W. H., \& Moreno, S. F. (2018). Prevention, mitigation and adaptation to climate change from perspectives of urban population in an emerging economy. Journal of Cleaner Production, 178(2018), 314-324. https://doi.org/10.1016/j.jclepro.2017.12.246

Mendizabal, M., Heidrich, O., Feliu, E., García-Blanco, G., \& Mendizabal, A. (2018). Stimulating urban transition and transformation to achieve sustainable and resilient cities. Renewable Sustainable Energy Review, 94(2018), 410-418. https://doi.org/10.1016/j.rser.2018.06.003

Mi, Z., Guan, D., Liu, Z., Liu, J., Vincent, Former, N., \& Wang, Y. (2019). Cities: The core of climate change mitigation. Journal of Cleaner Production, 207(2019), 582-589. https://doi.org/10.1016/j.jclepro.2018. 10.034

MPMAR- Ministry of Planning, Monitoring and Administrative Reform, 2018. Egypt's voluntary national review 2018. Cairo: Ministry of planning, monitoring and administrative reform. https://www.arabd evelopmentportal.com/sites/default/files/publication/vnr-egypt-2018.pdfAccessed, September 2021

NAP-GSP- National Adaptation Plan Global Support Programme, 2018. National adaptation plans in focus: Lessons from Egypt. Retrieved from UNDP: Climate change adaptation https://www.adaptation-undp. org/sites/default/files/resources/naps_in_focus_lessons_from_egypt.pdf.

Nevens, F., Frantzeskaki, N., Gorissen, L., \& Loorbach, D. (2013). Urban transition labs: Co-creating transformative action for sustainable cities. Journal of Cleaner Production, 50, 111-122. https://doi.org/10. 1016/j.jclepro.2012.12.001

Nyong, A., Adesina, F., \& Elasha, B. O. (2007). The value of indigenous knowledge in climate change mitigation and adaptation strategies in the African Sahel. Mitigation and Adaptation Strategies for Global Change, 12, 787-797. https://doi.org/10.1007/s11027-007-9099-0

Ostrom, E. (2010). Polycentric systems for coping with collective action and global environmental change. Global Environmental Change, 20(4), 550-557. https://doi.org/10.1016/j.gloenvcha.2010.07.004

Ozturk, T., Turp, M. T., Türkeş, M., \& Kurnaz, M. L. (2018). Future projections of temperature and precipitation climatology for CORDEX-MENA domain using RegCM4.4. Atmospheric Research, 206, 87-107. https://doi.org/10.1016/j.atmosres.2018.02.009 
Pasimeni, M. R., Valente, D., Zurlini, G., \& Petrosillo, I. (2019). The interplay between urban mitigation and adaptation strategies to face climate change in two European countries. Environmental Science and Policy, 95(2019), 20-27. https://doi.org/10.1016/j.envsci.2019.02.002

Percival, R. V., Schroeder, C. H., Miller, A. S., \& Leape, J. P. (2017). Environmental regulation: Law, science, and policy. Wolters Kluwer Law \& Business.

Schwirplies, C. (2018). Citizens' acceptance of climate change adaptation and mitigation: A survey in China, Germany, and the U.S. Ecological Economics, 145(2018), 308-322. https://doi.org/10.1016/j.ecolecon. 2017.11.003

Secinaro, S., et al. (2020). Employing bibliometric analysis to identify suitable business models for electric cars. Journal of Cleaner Production. https://doi.org/10.1016/j.jclepro.2020.121503

Seto, K.C., Dhakal, S., Bigio, A., Blanco, H., Delgado, G.C., Dewar, D., Huang, L., Inaba, A., Kansal, A., Lwasa, S., McMahon, J., Müller, D.B., Murakami, J., Nagendra, H., \& Ramaswami, A., 2014. Chapter 12 - Human settlements, infrastructure and spatial planning. In: Climate change 2014: Mitigation of climate change. IPCC working group III contribution to AR5, Cambridge University Press. http://www. ipcc.ch/pdf/assessment-report/ar5/wg3/ipcc_wg3_ar5_chapter12.pdf. Accessed September 2021.

Solecki, W., Seto, K., Balk, D., Bigio, A., Boone, C. G., Creutzig, F., Fragkias, M., Lwasa, S., Marcotullio, P., Romero-Lankao, P., \& Zwickel, T. (2015). A conceptual framework for an urban areas typology to integrate climate change mitigation and adaptation. Urban Climate, 14(2015), 116-137. https://doi.org/ 10.1016/j.uclim.2015.07.001

Su, Y., Yu, Y., \& Zhang, N. (2020). Carbon emissions and environmental management based on big data and streaming data: A bibliometric analysis. Science of the Total Environment, 733, 1-11. https://doi.org/10. 1016/j.scitotenv.2020.138984

Sugar, L., Kennedy, C., \& Hoornweg, D. (2013). Synergies between climate change adaptation and mitigation in development: Case studies of Amman, Jakarta, and Dar es Salaam. International Journal of Climate Change Strategies and Management, 5(1), 95-111. https://doi.org/10.1108/17568691311299381

Sweileh, W. M. (2021). Global research activity on elder abuse: A bibliometric analysis (1950-2017). Journal of Immigrant Minority Health, 23(2021), 79-87. https://doi.org/10.1007/s10903-020-01034-1

United Nations Department of Economic and Social Affairs, 2014. World Urbanization Prospects: The 2014 revision. https://population.un.org/wup/Publications/Files/WUP2014-Report.pdf. Accessed September 2021

UNDP- United Nations Development Program. (2011). Egypt's national strategy for adaptation to climate change and disaster risk reduction. UNDP.

UNDP- United Nations Development Program. (2018). Climate change Adaptation in the Arab states: Best practices and lessons learned. UNDP.

UNFCCC- United Nations Framework Convention on Climate Change, 2015. Paris Agreement, FCCC/ CP/2015/L.9/Rev.1. https://unfccc.int/resource/docs/2015/cop21/eng/109r01.pdf. Accessed September 2021

UN-Habitat. (2011). Global report on human settlements 2011 cities and climate change. Earthscan.

UN-Habitat, 2016. In: The world cities report: Urbanization and development (No. HS/ 038/16E). United Nations, 2017. New Urban Agenda, Quito, Ecuador.

UN-Habitat, 2016b. Arab strategy for housing and sustainable Urban development 2030. Retrieved from UNDP https://unhabitat.org/sites/default/files/2017/05/Arab-Strategy-English.pdf. Accessed September 2021

Van Eck, N. J., \& Waltman, L. (2009). Software survey: Vosviewer, a computer program for bibliometric mapping'. Scientometrics, 84(2), 523-538.

Van Eck, N.J., Waltman, L., 2019.Accuracy of citation data in Web of Science and Scopus. In: Proceedings of the 16th international conference of the international society for scientometrics and informetrics, 2019, pp. 1087-1092

WBG- World bank group. (2020). Climate risk country profile: Egypt. World Bank Publications.

WMO - World Meteorological Organization, 2020. WMO Statement on the State of the Global Climate in 2019. WMO https://reliefweb.int/sites/reliefweb.int/files/resources/WMO $\% 20$ Statement $\% 20$ on $\%$ 20the $\% 20$ State $\% 20$ of\%20the\%20Global\%20Climate\%20in\%202019.pdf. Accessed September 2021

Wu, Y., Shen, J., Zhang, X., Skitmore, M., \& Lu, W. (2016). The impact of urbanization on carbon emissions in developing countries: A Chinese study based on the U-Kaya method. Journal of Cleaner Production, $135,589-603$.

Xu, L., Wang, X., Liu, J., He, Y., Tang, J., Nguyen, M., \& Cui, S. (2019). Identifying the trade-offs between climate change mitigation and adaptation $\mathrm{T}$ in urban land use planning: An empirical study in a coastal city. Environment International, 133(2019), 105162. https://doi.org/10.1016/j.envint.2019.105162 
Zaki, A., Egyptian Meteorological Authority (EMA), Swelam, A., IWLMP, ICARDA, 2017. First report: Climatology of Nile Delta, Egypt.

Zen, I. S., Al-Amin, A., \& Doberstein, B. (2019). Mainstreaming climate adaptation and mitigation policy: Towards T multi-level climate governance in Melaka Malaysia. Urban Climate, 30(2019), 100501. https://doi.org/10.1016/j.uclim.2019.100501

Zupic, I., \& Carter, T. (2015). Bibliometric methods in management and organization. Organizational Research Methods, 18(3), 429-472. https://doi.org/10.1177/1094428114562629

Publisher's Note Springer Nature remains neutral with regard to jurisdictional claims in published maps and institutional affiliations.

\section{Authors and Affiliations}

\section{Marwa Dabaieh $^{1} \cdot$ Dalya Maguid $^{2} \cdot$ Rasha Abodeeb $^{3} \cdot$ Deena El Mahdy $^{2}$}

Dalya Maguid

dalya.maguid@gmail.com

Rasha Abodeeb

rashaabodeeb@gmail.com

Deena El Mahdy

deenaelmahdy@gmail.com

1 Malmo University, Malmö, Sweden

2 British University in Egypt, Cairo, Egypt

3 Ain Shams University, Cairo, Egypt 